\title{
Therapeutic effect of polysaccharide fraction of Atractylodis macrocephalae Koidz. in bovine subclinical mastitis
}

\author{
Wei Xu, Ran Guan, Yisong Lu, Xiaoyan Su, Ye Xu, Aifang Du and Songhua Hu*
}

\begin{abstract}
Background: Mastitis is considered the most significant and persistent disease in dairy cows, bringing about large economic losses. Subclinical mastitis brings about major cost implications, for it is difficult to detect due to absence of any visible indications and can persist in the mammary tissue throughout lactation. Immunomodulators have been widely used to reduce intramammary infections by modulating bovine mammary gland. Atractylodis macrocephalae Koidz. polysaccharides (RAMP), extracted from herbal medicine, has been used widely especially for its immunomodulatory function for many years. The objective of this study was to estimate an oil emulsified Atractylodis macrocephalae Koidz. polysaccharides (RAMP-O) as a potential therapeutic agent to treat subclinical mastitis by subcutaneous injection of RAMP-O in the area of supramammary lymph node in lactating cows via analysis of SCC, IMls and NAGase.

Results: Injection of RAMP-O in the area of supramammary lymph node significantly reduced milk SCC and NAGase activity compared with control. The quarters with bacterial infection were also progressively reduced in RAMP-O treated cows and only 9 quarters were found to have bacterial infection, while no obvious change was found in the control group.

Conclusions: Subcutaneous injection of RAMP-O in the area of supramammary lymph node had therapeutic value in the treatment of bovine subclinical mastitis by reducing SCC, NAGase and IMIs in milk. Considering both the therapeutic effect and the cost of RAMP-O, $32 \mathrm{mg}$ per dose was found most suitable to reduce milk SCC and NAGase. Therefore, RAMP-O deserves further study for its use in treatment of bovine mastitis.
\end{abstract}

Keywords: Atractylodis macrocephalae Koidz, Polysaccharides, Mastitis, Supramammary lymph node

\section{Background}

Mastitis is the most common disease of dairy cows and mainly caused by bacterial infection of the mammary gland [1-3]. Subclinical form cannot be detected by naked eyes with characteristics of increased SCC and decreased milk production [4-7]. In China, $40-80 \%$ of milking cows are subclinically infected, which account for the annual economic loss of more than 900 million dollars [8]. The antibiotic therapy is generally used for the treatment of mastitis, however it may lead to drug resistant bacteria and also attribute to residue in the human food chain [9]. In Sweden, antibiotic treatment

\footnotetext{
* Correspondence: songhua@zju.edu.cn

Department of Veterinary Medicine, College of Animal Sciences, Zhejiang University, 866 Yu Hang Tang Rd, Hang Zhou 310058, PR China
}

during lactation is not recommended in case of subclinical mastitis. Moreover, the use of antibiotic is on prescription only [10]. Therefore, looking for a novel alternative therapy for bovine mastitis is an urgent topic.

Since the end of 1980s, Sordillo and Daley [11] reviewed the use of cytokines as immunomodulators and potential therapeutic agents for mastitis therapy. Recombinant interferon- $\gamma$ has exhibited effectiveness in experimentally induced Escherichia coli and Staphylococcus aureus IMIs [12]. The extract from the root of Panax ginseng C.A. Meyer has been reported to have immunomodulatory property [13-15]. Intramammary infusion of ginseng saponins (GS) has been found to modulate the immunity of mammary gland by potentiating mRNA 
expression of proinflammatory cytokines (IL-1 $\alpha$, IL-1 $\beta$ and TNF- $\alpha$ ) in cows at drying off $[16,17]$.

Atractylodis macrocephalae Koidz. is a plant of Compositae having its natural resource in Zhejiang provinces in China. Its rhizome (RAM) has been used as a traditional Chinese medicine for about 2000 years [18]. $R A M$ consists of various active fractions, such as polysaccharides, volatile oil and lactones [19]. Previous investigation has shown that oral administration of the extract made from $R A M$ has enhanced immune responses of mice. Later investigation has shown that polysaccharides $(R A M P)$ extracted from $R A M$ is active for the immune enhancement. Recent research has shown that injection of RAMP together with foot-andmouth disease (FMD) vaccine significantly enhanced both humoral and cellular immune responses [20-22]. Therefore, we hypothesized that injection of RAMP may be useful in reduction of IMIs by stimulating the immunity in cows. The objective of this study was to estimate an oil emulsified $R A M P(R A M P-O)$ as a potential therapeutic agent to treat subclinical mastitis by subcutaneous injection of $R A M P-O$ in the area of supramammary lymph node in lactating cows via analysis of SCC, IMIs and NAGase.

\section{Results}

\section{Characterization of RAMP}

The polysaccharide contained in RAMP was $89.63 \%$ as measured by phenol-sulfuric acid method and it did not contain reducing sugar and starch-type polysaccharides on the basis of negative Fehling's reagent and iodine-potassium iodide reactions. UV analysis and triketohydrindene hydrate reaction showed that RAMP was not contaminated with protein. The FTIR spectrum of $R A M P$ measured in $\mathrm{KBr}$ pellets was shown in Fig. 1 . The characteristic strong broad band of absorption at $3386.08 \mathrm{~cm}^{-1}$ was attributed to $\mathrm{O}-\mathrm{H}$ stretching vibration of the polysaccharides. The band at $2929.71 \mathrm{~cm}^{-1}$ was ascribed to $\mathrm{C}-\mathrm{H}$ stretching vibration in carbohydrates and the band at $1633.08 \mathrm{~cm}^{-1}$ was due to the presence of bound water. The featured signal ester carbonyl groups at $1738.84 \mathrm{~cm}^{-1}$ suggested that RAMP was uronic acidcontained polysaccharide. The bands in the range of $1400-1200 \mathrm{~cm}^{-1}$ represented the variable-angle vibrations of $\mathrm{C}-\mathrm{H}$ in polysaccharides. The bands between 1031 and $1150 \mathrm{~cm}^{-1}$ were attributed to the stretching vibration of $\mathrm{C}-\mathrm{O}-\mathrm{C}$ group. The characteristic peak of absorption at $873.02 \mathrm{~cm}^{-1}$ was due to the variable-angle vibration of $\beta$-configuration $\mathrm{C}-\mathrm{H}$ of pyrnoase, while the band at $819.07 \mathrm{~cm}^{-1}$ was attributed to the variable-angle vibration of $\mathrm{C}-\mathrm{H}$ of furan ring. The absorption peak at $350-660 \mathrm{~cm}^{-1}$ indicated that it was a pyran-type polysaccharide. The ${ }^{1} \mathrm{H}$ NMR spectrum of RAMP was shown in Fig. 2. In general, the vibrations at $\delta 4.8-5.3 \mathrm{ppm}$ indicate that the polysaccharide has an $\alpha$-configuration, while the vibrations of a $\beta$-configuration are at $\delta 4.0-4.8 \mathrm{ppm}$. The signals of $R A M P$ showed that it was a polysaccharide with both $\alpha$ and $\beta$ configurations, but the $\beta$-configuration was dominant.

\section{Stability and viscosity of RAMP-O}

No separation was observed between aqueous and oil phases after $R A M P-O$ was centrifuged for $15 \mathrm{~min}$ at

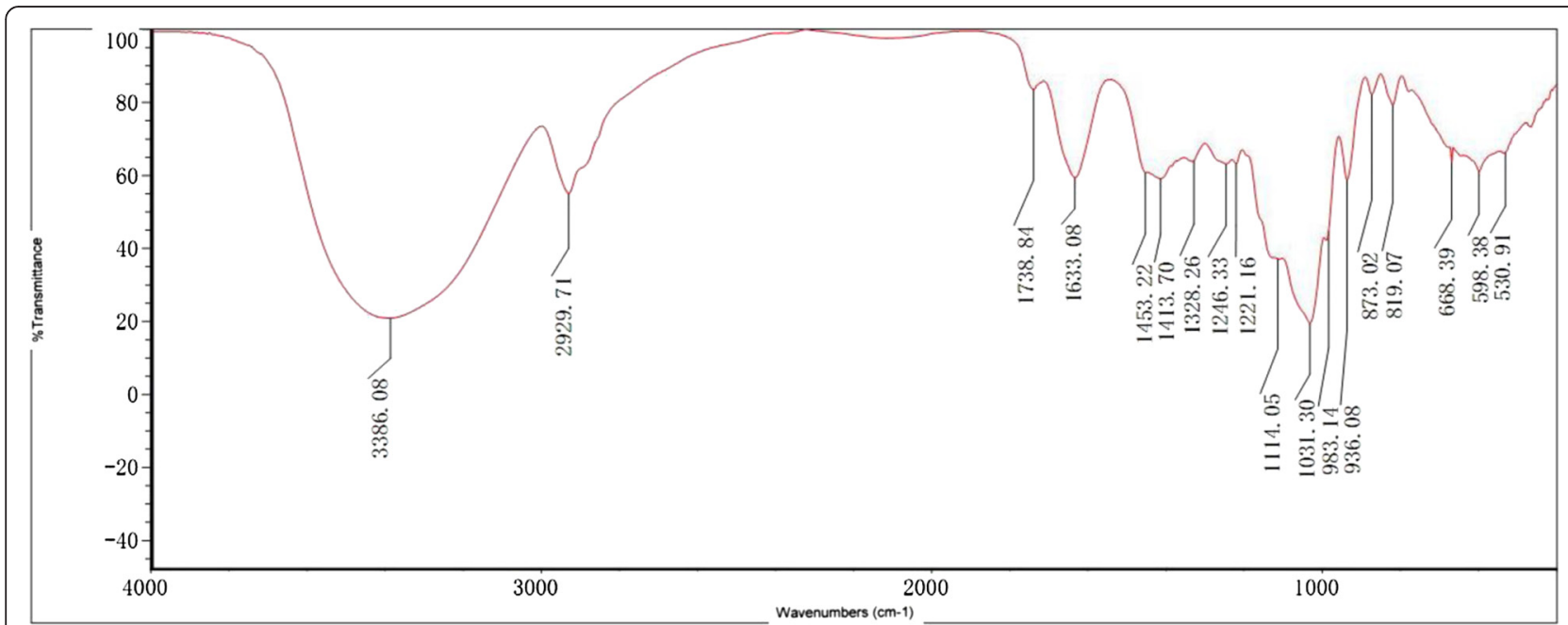

Fig. 1 FTIR spectroscopy of RAMP. The FITR spectrum of RAMP showed a strong broad band of absorption at $3386.08 \mathrm{~cm}^{-1}$ attributed to $\mathrm{O}-\mathrm{H}$ stretching vibration of the polysaccharides. The band at $2929.71 \mathrm{~cm}^{-1}$ was ascribed to $\mathrm{C}-\mathrm{H}$ stretching vibration in carbohydrates and the band at $1633.08 \mathrm{~cm}^{-1}$ was due to the presence of bound water. The characteristic peak of absorption at $873.02 \mathrm{~cm}^{-1}$ was due to the variable-angle vibration of $\beta$-configuration $\mathrm{C}-\mathrm{H}$ of pyranose. The band at $819.07 \mathrm{~cm}^{-1}$ was attributed to the variable-angle vibration of $\mathrm{C}-\mathrm{H}$ of furan ring. The absorption peak at $350-660 \mathrm{~cm}^{-1}$ indicated that it was a pyran-type polysaccharide 


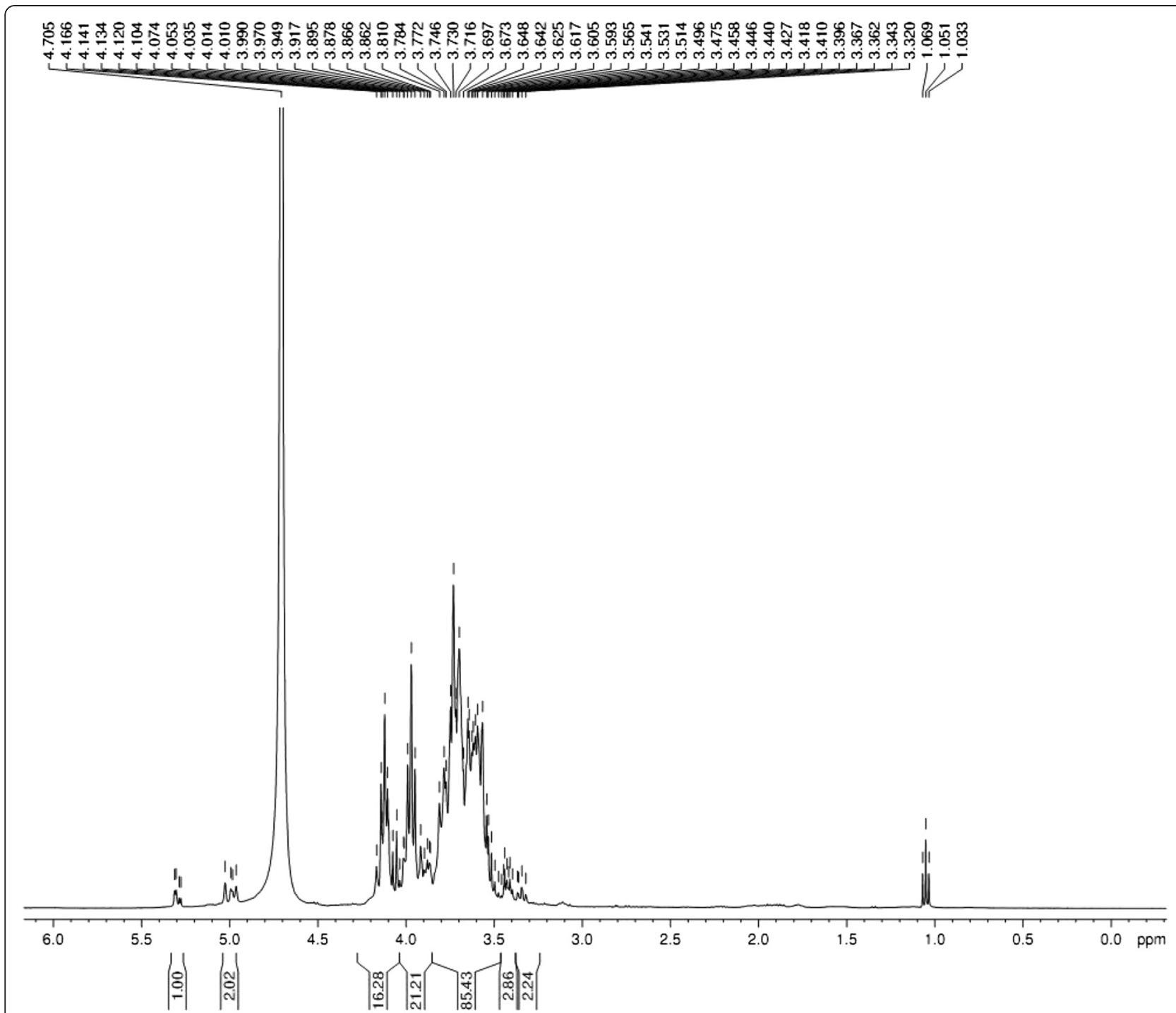

Fig. $2{ }^{1} \mathrm{H}$ NMR spectrum of RAMP. The ${ }^{1} \mathrm{H}$ NMR spectra showed that RAMP was a polysaccharide with both a and $\beta$ configurations, while the $\beta$-configuration is dominant

$4000 \mathrm{rpm}$; it took $7.8 \pm 0.4 \mathrm{~s}, 7.6 \pm 0.3 \mathrm{~s}$ and $8.1 \pm$ $0.4 \mathrm{~s}$, respectively, for the oil emulsion containing 4,8 and $12 \mathrm{mg}$ of $R A M P$ per $\mathrm{ml}$ to flow out of the pipette, indicating that $R A M P-O$ had a low viscosity.

Irritation induced by subcutaneous injection of RAMP-O in the area of supramammary lymph node

Initially, we injected $32 \mathrm{mg}$ of $R A M P-O$ in a clinically healthy cow with milk SCC of $220,000 / \mathrm{ml}$. No visible local reactions were observed at the injection site and no obvious change of SCC was detected in composite milk during 3 days following that injection (Fig. 3). Additionally, no side effects were found at the injection site throughout experiments 1 and 2 .
Simultaneous injections of RAMP-O in both left and right areas of the supramammary lymph node reduced SCC and NAGase activity in milk

In experiment 1 , low (16 mg), middle (32 mg) and high (48 mg) doses of $R A M P-O$ were used for injection in the area of the supramammary lymph node in groups 1 to 3 . During three weeks after the treatment, both SCC and NAGase activity in milk were progressively declined in groups 1 to 3 (Tables 1 and 2). Although there was no significant difference among the three groups, the highest decrease was found in groups 2 and 3. Compared with the control, SCC decreased by $45.3 \%$ and $46.0 \%$, respectively, in groups 2 and 3; NAGase decreased by $55.2 \%$ and $60.3 \%$, respectively, in groups 2 and 3. Since there were no significant difference between the two 


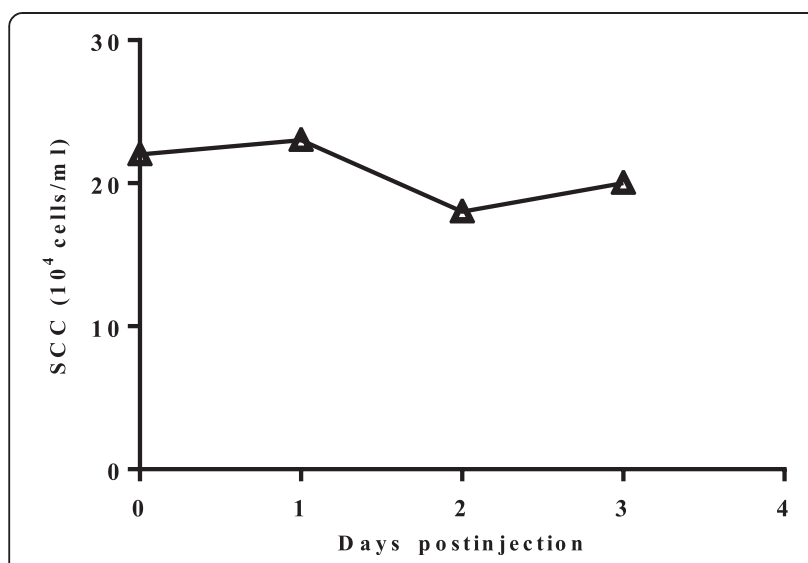

Fig. 3 Irritancy of RAMP-O on milk SCC. SCC of composite milk in cows before and after subcutaneous injection of RAMP-O in left and right areas of supramammary lymph node in cow 435

groups, $32 \mathrm{mg}$ of $\mathrm{RAMP}-\mathrm{O}$ was used in our subsequent study.

Similar results were observed in experiment 2. Injection of RAMP-O (32 mg) significantly reduced SCC and NAGase in milk (Tables 3 and 4). In addition, significantly reduced SCC was also found in composite milk when compared to the control group (Table 5).

\section{Changes of bacteria infected quarters before and after treatment}

Before treatment, bacteria were isolated from 21 quarter milk samples in $R A M P-O$ treated cows while 23 quarters were found to have bacterial infection in the control (Table 6). There was no statistical difference between the 2 groups. The isolated bacteria were Staphylococcus aureus, Streptococcus agalactiae, Streptococcus dysgalactiae, Streptococcus uberis, coagulase-negative staphylococci (CNS), and others. After treatment, the quarters with bacterial infection were progressively reduced in $R A M P-O$ treated cows and only 9 quarters were found to have bacterial infection, while no obvious change was found in the control group.

\section{Discussion}

In this study, we demonstrated a therapeutic effect of oil emulsified polysaccharide fraction of Atractylodis macrocephalae Koidz. (RAMP-O) on bovine subclinical mastitis. The use of immunomodulators to modulate bovine mammary gland has been previously reported. For example, it was found that intramammary administration of antibiotics in combination with recombinant bovine IL-2 for Staphylococcus aureus IMIs improved therapeutic efficacy by 20-30\% [23]. Ginseng saponins (GS) has been reported to stimulate lymphocyte proliferation and PMN phagocytosis from bovine peripheral blood and milk [13-15]. Recently, intramammary infusion of GS significantly increased IL- $1 \alpha$, IL- $1 \beta$ and TNF- $\alpha$ mRNA expression in cows at drying off $[16,17]$. In the present study, the number of infected quarters was significantly reduced after $R A M P-O$ treatment. As $R A M P$ $O$ itself has no antibacterial activity, the diminished IMIs may be attributed to its immunomodulatory property.

RAMP was extracted from the rhizome of Atractylodis macrocephalae Koidz. The drug is traditionally orally administered for the treatment of diarrhea and infections in humans and animals. Zhou [24] reported a successful treatment of chronic respiratory infections using Shen Ling Bai Zhu San (codonopsis, atractylodes, poria, paeonia, nelumbo, dolichoris, coix, amomum, platycodon, citrus, aster, fritillaria and glycerrhiza) with an effective rate of $96 \%$. Oral administration of the soup or $R A M P$ made from the rhizome has significantly enhanced the immune responses of mice to a model protein antigen ovalbumin or FMD vaccine [21, 25]. In 2013, Chai found an enhanced antibody response to ovalbumin by injection of $R A M P$ with the antigen. Therefore, both oral and parental administrations of $R A M P$ can improve the immune response. Chemical study has shown that $R A M P$ is composed of rhamnose, arabinose, xylose, mannose, glucose, and galactose with molar ratios of 1.00: 2.49: 2.07: 4.94: 11.33: 1.35 [21]. In this study, we further analyzed the structure of $R A M P$ using FTIR and ${ }^{1} \mathrm{H}$ NMR spectra and the results indicated that it was a polysaccharide with both $\alpha$ - and $\beta$-configurations, while the

Table 1 Influence of RAMP-O on composite milk SCC

\begin{tabular}{|c|c|c|c|c|c|}
\hline \multirow[t]{2}{*}{ RAMP-O (mg) } & \multirow[t]{2}{*}{ No. of cows } & \multicolumn{4}{|c|}{ Weeks post treatment } \\
\hline & & $\overline{0^{\dagger}}$ & 1 & 2 & 3 \\
\hline 16 & 6 & $73.01 \pm 10.05$ & $65.79 \pm 5.96$ & $63.62 \pm 17.94 a^{*}$ & $54.65 \pm 16.66 a^{* *}$ \\
\hline 32 & 6 & $72.93 \pm 18.42$ & $62.31 \pm 19.10$ & $46.54 \pm 25.14 a$ & $42.34 \pm 21.30 a^{*}$ \\
\hline 48 & 6 & $71.48 \pm 16.07$ & $49.85 \pm 23.49$ & $45.01 \pm 17.57 A^{* *}$ & $41.83 \pm 14.81 \mathrm{~A}^{*}$ \\
\hline Control & 6 & $76.39 \pm 14.38$ & $77.20 \pm 13.81$ & $85.17 \pm 12.15$ & $77.47 \pm 14.24$ \\
\hline
\end{tabular}

SCC of composite milk in cows before and after subcutaneous injection of RAMP-O in the areas of supramammary lymph node (mean \pm S.E. $10^{4}$ cells/ml) $\mathrm{a} P<0.05, \mathrm{~A} P<0.01$, compared with the control in the same time

${ }^{*} P<0.05$, ${ }^{*} P<0.01$, compared with pretreatment

${ }^{\dagger}$ Pretreatment 
Table 2 Influence of RAMP-O on composite milk NAGase

\begin{tabular}{llllll}
\hline RAMP-O $(\mathrm{mg})$ & No. of cows & \multicolumn{4}{l}{ Weeks post treatment } \\
\cline { 3 - 6 } & & $0^{\dagger}$ & 1 & 2 & 3 \\
\hline 16 & 6 & $52.07 \pm 12.50$ & $46.75 \pm 10.09^{*}$ & $46.31 \pm 9.79^{*}$ & $33.91 \pm 9.27 \mathrm{a}^{*}$ \\
32 & 6 & $52.46 \pm 12.24$ & $46.18 \pm 9.49^{*}$ & $25.36 \pm 6.77 \mathrm{~A}^{* *}$ & $23.79 \pm 5.47 \mathrm{~A}^{* *}$ \\
48 & 6 & $52.11 \pm 11.35$ & $27.27 \pm 8.09 \mathrm{~A}^{* *}$ & $24.97 \pm 6.85 \mathrm{~A}^{* *}$ & $21.09 \pm 3.44 \mathrm{~A}^{* *}$ \\
Control & 6 & $52.66 \pm 12.12$ & $52.90 \pm 12.07$ & $55.09 \pm 11.73$ & $53.13 \pm 11.81$ \\
\hline
\end{tabular}

NAGase of composite milk in cows before and after subcutaneous injection of RAMP-O in the areas of supramammary lymph node (mean \pm S.E. U/L) $\mathrm{a} P<0.05, \mathrm{~A} P<0.01$, compared with the control in the same time

${ }^{*} P<0.05$, ${ }^{*} P<0.01$, compared with pretreatment

${ }^{\dagger}$ Pretreatment

main component was $\beta$-configuration. Previous investigations have shown that many polysaccharides isolated from herbs possess biological activities [26-28]. For example, the polysaccharides isolated from the root of Astragalus membranaceus have a backbone structure composed of glucoses and have been widely used for their immunomodulatory activities [25, 29, 30]. RAMP has been demonstrated to have the similar polysaccharide structure which may contribute to the therapeutic effect of $R A M P-O$ on bovine subclinical mastitis.

Subcutaneous injection of $R A M P-O$ in the area of supramammary lymph node significantly reduced milk SCC, NAGase and IMIs in subclinically infected lactating cows.

Mastitis is the most common disease of dairy cows. It is characterized by pathological alterations in the mammary tissues and compositional changes in the milk [31]. The economic losses caused by mastitis continue to bring heavy burden to dairy farm. Although current practices have reduced its occurrence, the disease remains heavily prevalent in many dairy herds [32]. Mastitis is mainly caused by invasion of bacteria in the mammary gland. When bacteria break through the physical barrier of teat canal, they encounter the second line of defense built by humoral and cellular protective factors of the mammary gland [12]. The humoral factors include immunoglobulin, complement, lactoferrin, lysozyme, lactoperoxidase system and so on while the cellular factors consist of macrophages, polymorphonuclear leukocytes (PMN), lymphocytes, etc. [33]. If the bacteria are virulent enough, they will settle in the mammary gland and establish the infection. The invading bacteria release chemotactic factors to attract large number of PMN flux into the mammary gland from blood stream, causing dramatically increased milk SCC up to millions of cells per ml of milk. Increased SCC is frequently used as an indicator for the intramammary inflammation [34]. In this study, we showed that subcutaneous injection of $R A M P-O$ in the areas of supramammary lymph node in subclinically mastitic cows significantly reduced milk SCC in both experiments 1 and 2 with the largest scope in decrease found in the cows injected with 32 or $48 \mathrm{mg}$ of RAMP-O. The decrease in milk SCC may be attributed to diminished IMIs as less infected quarters were observed in cows treated with $R A M P-O$ than the control as demonstrated in experiment 2.

NAGase is an intracellular lysosomal enzyme which is released into milk from neutrophils during phagocytosis and cell lysis [35]. NAGase is mostly located in PMN and thus freezing and thawing of the milk samples are used for a maximal release of the enzyme [36]. The enhanced phagocytes in the mammary gland is correlated with the increase of the enzyme. Therefore, Milk NAGase is used as an indicator for IMIs. A successful antibiotic treatment could result in decrease of milk NAGase activity [37]. In the present study, significantly decreased NAGase (Tables 2 and 4) could be explained by reduced milk SCC which could be due to declined IMIs following $R A M P-O$ treatment.

\section{Conclusions}

After observing the above results, we concluded that subcutaneous injection of $R A M P-O$ in the areas of supramammary lymph node had therapeutic value in the

Table 3 Influence of RAMP-O on quarter milk SCC

\begin{tabular}{lllll}
\hline Group & No. of quarters & & \\
\cline { 3 - 5 } & & $0^{\dagger+}$ & 1 & 2 \\
\hline RAMP-O & 14 & $63.39 \pm 21.92$ & $48.59 \pm 27.52$ & $40.18 \pm 11.79 a^{*}$ \\
Control & 12 & $60.32 \pm 10.20$ & $54.53 \pm 53.63$ & $70.64 \pm 67.24$ \\
\hline
\end{tabular}

SCC of quarter milk in cows before and after subcutaneous injection of RAMP-O in the areas of supramammary lymph node (mean \pm S.E. $10^{4}$ cells $/ \mathrm{ml}$ ) $\mathrm{a} P<0.05$, compared with the control in the same time

${ }^{*} P<0.05$, compared with pretreatment

${ }^{\dagger}$ Pretreatment

${ }^{+t}$ The quarter had milk with SCC more than 500,000 cells $/ \mathrm{ml}$ and positive bacterial examination before treatment 
Table 4 Influence of RAMP-O on quarter milk NAGase

\begin{tabular}{llllll}
\hline Group & No. of quarters & & & \\
\cline { 3 - 5 } & & $0^{\dagger+}$ & 1 & 2 & 3 \\
\hline RAMP-O & 14 & $43.03 \pm 26.69$ & $23.75 \pm 8.91 a^{*}$ & $22.16 \pm 9.59 a^{* *}$ & $17.86 \pm 4.36 a^{* *}$ \\
Control & 12 & $38.01 \pm 9.00$ & $36.12 \pm 28.89$ & $76.30 \pm 83.06^{* *}$ & $61.59 \pm 75.76$ \\
\hline
\end{tabular}

NAGase of quarter milk in cows before and after subcutaneous injection of RAMP-O in the areas of supramammary lymph node (mean \pm S.E. U/L)

$\mathrm{a} P<0.05$, compared with the control in the same time

${ }^{*} P<0.05,{ }^{*} P<0.01$, compared with pretreatment

${ }^{\dagger}$ Pretreatment

${ }^{+\dagger}$ The quarter had milk with SCC more than $500,000 \mathrm{cells} / \mathrm{ml}$ and positive bacterial examination before treatment

treatment of bovine subclinical mastitis by reducing SCC, NAGase and IMIs in milk. Considering the therapeutic effect and the cost of $R A M P-O, 32 \mathrm{mg}$ per dose was found most suitable to reduce milk SCC and NAGase. Therefore, $R A M P-O$ needs further study for its use in treatment of bovine mastitis.

\section{Methods}

\section{Extraction of polysaccharide fraction of Atractylodis} macrocephalae Koidz. polysaccharides (RAMP)

Dried rhizome of Atractylodis macrocephalae Koidz. was purchased from Hu Qing Yu Tang Co. Ltd, Hangzhou, China. The polysaccharide fraction was extracted as per the method described earlier [21]. Briefly, the rhizome $(100 \mathrm{~g})$ was ground into powder and boiled twice under reflux for $2 \mathrm{~h}$ each time. The aqueous portion was filtered through filter paper. The filtrate was concentrated under reduced pressure, and then centrifuged at $3000 \mathrm{rpm}$ for $15 \mathrm{~min}$. Four volumes of $95 \%$ ethanol were added to the supernatant, and kept overnight at $4{ }^{\circ} \mathrm{C}$. The resulting precipitate was dissolved in distilled water, subjected to Macroporous Adsorption Resin column D101, and then washed with water. The collected elute was concentrated, dialyzed against distilled water (cut-off $\mathrm{Mw} 7000 \mathrm{Da}$ ) and lyophilized to afford a total polysaccharide (RAMP, light off-white powder, $8.53 \mathrm{~g}$ ). Total sugar content was estimated by the phenol-sulfuric acid analysis using glucose as a standard [38]. Transmission Fourier transform infrared spectroscopy (FTIR) was conducted using Thermo NICOLET is5 (Nicolet Instrument, Thermo Company, USA). The RAMP samples were incorporated into $\mathrm{KBr}$ (spectroscopic grade) and pressed into a 1-mm pellet for FTIR measurement between 400 and $4000 \mathrm{~cm}^{-1}$. ${ }^{1} \mathrm{H}$ NMR spectra of solutions in $\mathrm{D}_{2} \mathrm{O}$ was recorded at ambient

Table 5 Influence of RAMP-O on SCC of composite milk

\begin{tabular}{llll}
\hline Group & No. of cows & Pretreatment & Posttreatment \\
\hline RAMP-O & 11 & $62.55 \pm 25.38$ & $29.21 \pm 6.85 a^{*}$ \\
Control & 11 & $56.66 \pm 32.34$ & $54.89 \pm 11.88$
\end{tabular}

SCC of composite milk in cows before and after subcutaneous injection of $R A M P-O$ in the areas of supramammary lymph node (mean \pm S.E. $10^{4}$ cells $/ \mathrm{ml}$ ) a $P<0.05$, compared with the control in the same time

${ }^{*} P<0.05$, compared with pretreatment temperature using Bruker AranceIII 400 M (Bruker, Switzerland).

\section{Rapeseed oil}

Rapeseed oil was the product of the Shanghai Jiali Food Industry Co. Ltd, Shanghai, China, and manufactured according to Standard GB1536.

\section{Oil emulsified Atractylodis macrocephalae Koidz. polysaccharides (RAMP-O)}

To produce oil emulsified $R A M P$, oil phase was prepared by mixing rapeseed oil with Span-80 to make an oil containing $14 \%$ of Span-80; aqueous phase was prepared by addition of Tween-80 to RAMP solution to produce an $R A M P$ solution containing $8 \%$ of Tween- 80 with 12,24 or $36 \mathrm{mg}$ of $R A M P$ per $\mathrm{ml}$. Then the oil phase was emulsified in the aqueous phase at 2: $1(\mathrm{v} / \mathrm{v})$ with a dispersing device (B. R. T TECHNOLOGY B25 Laboratory Series) to produce oil emulsified RAMP (RAMP-O). Each milliliter of $R A M P-O$ contained $R A M P$ of 4,8 and $12 \mathrm{mg}$, respectively.

\section{Test of stability and viscosity}

To test the stability of $R A M P-O$, sample was observed if there was any separation between aqueous and oil phases after centrifuged at $4000 \mathrm{rpm}$ for $15 \mathrm{~min}$; to test the viscosity of $R A M P-O$, the time required for $0.4 \mathrm{ml}$ of

Table 6 Influence of RAMP-O on bacteria

\begin{tabular}{|c|c|c|c|c|c|c|c|c|}
\hline \multirow[t]{3}{*}{ Bacterium } & \multicolumn{8}{|c|}{ Weeks post treatment } \\
\hline & \multicolumn{4}{|c|}{ RAMP-O } & \multicolumn{4}{|c|}{ Control } \\
\hline & $\overline{0^{\dagger}}$ & 1 & 2 & 3 & $\overline{0^{\dagger}}$ & 1 & 2 & 3 \\
\hline Staphylococcus aureus & 7 & 6 & 4 & $3^{*}$ & 6 & 5 & 6 & 6 \\
\hline Streptococcus agalactiae & 3 & 2 & 2 & 2 & 4 & 4 & 4 & 4 \\
\hline Streptocossus dysgalactiade & 1 & 1 & 0 & 0 & 2 & 1 & 1 & 1 \\
\hline Streptococcus uberis & 3 & 3 & 1 & 1 & 1 & 1 & 1 & 1 \\
\hline $\mathrm{CNS}^{\#}$ and others & 7 & 7 & 5 & $3^{*}$ & 10 & 9 & 10 & 10 \\
\hline Total & 21 & 19 & $12^{*}$ & $9^{*}$ & 23 & 20 & 22 & 22 \\
\hline
\end{tabular}

Milk samples with positive bacterial examination (tested quarters: 41 in RAMP-O; 44 in control)

${ }^{*} P<0.05$, compared with pretreatment

${ }^{\dagger}$ Pretreatment

"CNS, coagulase negative staphylococci 
RAMP-O sample to flow out of the 1-ml pipette positioned vertically was recorded.

\section{Irritancy test of RAMP-O}

The cow 435 for the irritancy test was in her second mid lactation and clinically healthy. Each of four quarters had milk sample of SCC less than 500,000 cells/ml and negative bacteriological examination. Subcutaneous injection of $R A M P-O$ at a dose of $32 \mathrm{mg}$ in the area of supramammary lymph node was administered once after morning milking bilaterally. The injection sites were closely observed and milk samples were collected daily within 3 days after injection for SCC analysis.

\section{Selection of cows}

This experiment was approved by the Institutional Animal Care and Use Committee at Zhejiang University and was conducted in accordance with the National Institutes of Health guidelines for the care and use of experimental animals. The therapeutic experiment was performed on a dairy farm in Jinhua, Zhejiang, China, having approximately 2,000 Holstein dairy cows that were machined-milked twice daily. The cows used in experiment 1 had SCC of composite milk more than 500,000 cells $/ \mathrm{ml}$, while the cows in experiment 2 had at least one quarter having positive bacterial examination and SCC more than 500,000 cells $/ \mathrm{ml}$.

\section{Experimental design Experiment 1}

A total of 24 lactating Holstein cows were used. They were randomly allocated into 4 groups with 6 animals in each. Groups 1 to 3 were subcutaneously injected with $R A M P-O$ in the area of the supramammary lymph node after morning milking at the dose of 16,32 or $48 \mathrm{mg}$, respectively. Each cow received a half dose injected at left side and the other half dose at right side. Group 4 received no treatment and served as a control. Composite milk was sampled from each cow before and 1, 2, 3 weeks after $R A M P-O$ treatment for determination of SCC and NAGase.

\section{Experiment 2}

A total of 22 clinically healthy lactating Holstein cows with at least one quarter suffering from subclinical mastitis were used. The cows were randomly allocated into 2 groups: group 1 had 11 cows whose 14 of 41 quarters were subclinically infected; group 2 had 11 cows whose 12 of 44 quarters were subclinically infected. Groups 1 received a subcutaneous injection of $R A M P-O(16 \mathrm{mg})$ in the left supramammary lymph node and the same amount of $R A M P-O$ injected in the right supramammary lymph node after morning milking. The decision to use $32 \mathrm{mg}$ of $R A M P-O$ per dose was based on the balance between the cost of $R A M P-O$ and the therapeutic effects found in experiment 1 in which no statistically significant difference was found between groups of 32 and $48 \mathrm{mg}$. Group 2 received no treatment and served as a control. Quarter milk samples were collected before and 1, 2, 3 weeks after RAMP-O treatment for bacteriological, SCC and NAGase analysis. Composite milk samples were collected before and one month after $\mathrm{RAMP}-\mathrm{O}$ treatment.

\section{Estimation of somatic cell count (SCC)}

For analysis of SCC, milk samples were heated to 40$42{ }^{\circ} \mathrm{C}$. After shaking well, the samples were analyzed by Fossomatic Minor instrument (Foss Electric, Hillerod, Denmark).

\section{Bacteriological examination}

Milk samples were streaked on blood agar plates and incubated aerobically at $37^{\circ} \mathrm{C}$ for 24 to $48 \mathrm{~h}$. After the culture, the plates were observed for primary isolation of bacteria. A milk sample was considered contaminated if 3 or more different bacterial colonies of bacteria were found. Afterward, a single colony on the blood agar was collected into nutrient broth medium and cultured for 18-24 h at $37{ }^{\circ} \mathrm{C}$. Further identification of specific bacterial species such as staphylococci, streptococci, and gram-negative bacteria was carried out based on the methods described by the National Mastitis Council [39, 40].

\section{$\mathrm{N}$-acetyl- $\beta$-D-glucosaminidase test}

Milk samples were frozen and thawed for 3 times to liberate NAGase from cells and next centrifuged at $3,500 \mathrm{rpm}$ for $20 \mathrm{~min}$ to eliminate cream layer. The skim milk was regulated to $\mathrm{pH} 4.6$ by adding $10 \%$ acetic acid and centrifuged at 3,500 rpm for $20 \mathrm{~min}$ to obtain whey. The NAGase in whey was measured by commercial kits (Nanjing Jiancheng Bioengineering Institute, Jiangsu, China) according to the manufacturer's protocol. The OD value of paranitrophenol during the reaction (at $37{ }^{\circ} \mathrm{C}$ ) between the 4-methylumbelliferyl- $\mathrm{N}$-acetyl- $\beta$-glucosaminide substrate and the NAGase in the samples was estimated spectrophotometrically in triplicate at $400 \mathrm{~nm}$. One unit of NAGase activity stands for the amount of paranitrophenol liberated from 1 liter of whey in $15 \mathrm{~min}$ at $37^{\circ} \mathrm{C}$.

\section{Statistical analyses}

Data were analyzed by SPSS 20.0 software for windows and expressed as means \pm standard error (S.E.). Independent-sample $t$ test was performed to evaluate the differences between the data of $R A M P-O$ treated group and the control. Paired-sample $t$ test was carried out to compare the differences between the data of pretreatment and posttreatment. Chi-square analysis was used to compare the number of quarters infected with 
same bacteria in the same group between pretreatment and posttreatment. $P$ values of less than 0.05 were considered statistically significant.

\begin{abstract}
Abbreviations
RAMP: Atractylodis macrocephalae Koidz. polysaccharides; RAMP-O: Oil emulsified Atractylodis macrocephalae Koidz. polysaccharides; SCC: Somatic cell count; IMIs: Intramammary infections; NAGase: N-Acetyl- $\beta$-Dglucosaminidase; CNS: Coagulase-negative staphylococci; GS: Ginseng saponins; FTIR: Transmission Fourier transform infrared spectroscopy; NMR: Nuclear magnetic resonance; PMN: Polymorphonuclear leukocyte.
\end{abstract}

\section{Competing interests}

The authors declare that they have no competing interests.

\section{Authors' contributions}

All authors participated in the draft of the manuscript. Moreover, WX, RG, YSL, XYS and XY carried out the sampling collection, microbiological isolation and biochemical identification; WX and YSL conducted the preparation of RAMP-O; WX and XYS performed statistical analysis; and $\mathrm{SHH}$ and AFD conceived, designed, and coordinated the study, and wrote the final manuscript. All authors read and approved the final manuscript.

\section{Acknowledgements}

We gratefully acknowledge the participation of the owners and veterinarians of Yi Kang Dairy Farm. The authors also acknowledge the Zhejiang Province Science and Technology Correspondent Special Team (2012T2T2109) for the financial support.

\section{Received: 13 January 2015 Accepted: 16 July 2015}

Published online: 25 July 2015

\section{References}

1. Bannerman DD. Pathogen-dependent induction of cytokines and other soluble inflammatory mediators during intramammary infection of dairy cows. J Anim Sci. 2009:87(13 suppl):10-25.

2. Gonen E, Vallon Eberhard A, Elazar S, Harmelin A, Brenner O, Rosenshine I, et al. Toll-like receptor 4 is needed to restrict the invasion of Escherichia coll P4 into mammary gland epithelial cells in a murine model of acute mastitis. Cell Microbiol. 2007;9(12):2826-38.

3. Hawari AD, Al-Dabbas F. Prevalence and distribution of mastitis pathogens and their resistance against antimicrobial agents in dairy cows in Jordan Am J Anim Vet Sci. 2008;3(1):36.

4. Dohoo IR, Meek AH. Somatic cell counts in bovine milk. Can Vet J. 1982;23(4):119

5. Gröhn YT, Wilson DJ, González RN, Hertl JA, Schulte H, Bennett G, et al. Effect of pathogen-specific clinical mastitis on milk yield in dairy cows. J Dairy Sci. 2004;87(10):3358-74.

6. Pilla R, Malvisi M, Snel GM, Schwarz D, König S, Czerny C, et al. Differential cell count as an alternative method to diagnose dairy cow mastitis. J Dairy Sci. 2013;96(3):1653-60.

7. Schukken YH, Lam TJ, Nielen M, Hogeveen H, Barkema HW, Grommers FJ. Subclinical and clinical mastitis on dairy farms in The Netherlands: epidemiological developments. Tijdschr Diergeneesk. 1995;120(7):208-13.

8. Memon J, Kashif J, Yaqoob M, Liping W, Yang Y, Hongjie F. Molecular characterization and antimicrobial sensitivity of pathogens from sub-clinical and clinical mastitis in Eastern China. Pak Vet J,33(2):170-174.

9. Cao LT, Wu JQ, Xie F, Hu SH, Mo Y. Efficacy of nisin in treatment of clinical mastitis in lactating dairy cows. J Dairy Sci. 2007;90(8):3980-5.

10. Persson Y, Nyman AJ, Grönlund-Andersson U. Etiology and antimicrobial susceptibility of udder pathogens from cases of subclinical mastitis in dairy cows in Sweden. Acta Vet Scand. 2011;53(1):36.

11. Sordillo L, Daley M. Role of cytokines in the prevention and treatment of bovine mastitis (1995). In: Myers MJ, Murtaugh MP, editors. Cytokines in animal health and disease. New York: Marcel Dekker Publ; 1995.

12. Pyörälä S. New strategies to prevent mastitis. Reprod Domest Anim. 2002:37(4):211-6.

13. Concha C, Hu S, Holmberg O. The proliferative responses of cow stripping milk and blood lymphocytes to pokeweed mitogen and ginseng in vitro. Vet Res. 1996;27(2):107-15.
14. Hu S, Concha C, Cooray R, Holmberg O. Ginseng-enhanced oxidative and phagocytic activities of polymorphonuclear leucocytes from bovine peripheral blood and stripping milk. Vet Res. 1995;26(3):155-61.

15. Hu S, Concha C, Johannisson A, Meglia G, Waller KP. Effect of subcutaneous injection of ginseng on cows with subclinical Staphylococcus aureus mastitis. J Vet Med B. 2001:48(7):519-28.

16. Baravalle C, Dallard BE, Cadoche MC, Pereyra E, Neder VE, Ortega HH, et al. Proinflammatory cytokines and CD14 expression in mammary tissue of cows following intramammary inoculation of Panax ginseng at drying off. Vet Immunol Immunop. 2011;144(1):52-60.

17. Baravalle C, Dallard BE, Ortega HH, Neder VE, Canavesio VR, Calvinho LF. Effect of Panax ginseng on cytokine expression in bovine mammary glands at drying off. Vet Immunol Immunop. 2010;138(3):224-30.

18. Chen W, He GF, Jiang MH, Qiu XM. Advances of the rhizome of Atractylodis macrocephalae Koidz, during the recent decades. Lishizhen Med Met Medica Res. 2007;18(2):338-40.

19. Duan Q, Xu DJ, Liu CX, Li CL. Advances of the rhizome of Atractylodis macrocephalae Koidz. Chinese Tradit Herbal Drugs. 2008:39(5):4-6.

20. Li R, Sakwiwatkul K, Yutao L, Hu S. Enhancement of the immune responses to vaccination against foot-and-mouth disease in mice by oral administration of an extract made from Rhizoma Atractylodis Macrocephalae (RAM). Vaccine. 2009;27(15):2094-8.

21. Xie F, Li Y, Su F, Hu S. Adjuvant effect of Atractylodis macrocephalae Koidz. polysaccharides on the immune response to foot-and-mouth disease vaccine. Carbohyd Polym. 2012;87(2):1713-9.

22. Xie F, Sakwiwatkul K, Zhang C, Wang Y, Zhai L, Hu S. Atractylodis macrocephalae Koidz. polysaccharides enhance both serum IgG response and gut mucosal immunity. Carbohyd Polym. 2013;91(1):68-73.

23. Daley MJ, Furda G, Dougherty R, Coyle PA, Williams TJ, Johnston P. Potentiation of antibiotic therapy for bovine mastitis by recombinant bovine interleukin-2. J Dairy Sci. 1992;75(12):3330-8.

24. Zhou MY. Shen Ling Bai Zhu San in treatment of 125 cases with infections in the upper respiratory tract. Sci Technol Chin Mater Medica. 2001;8(2):68

25. Li R, Chen W, Wang W, Tian W, Zhang X. Extraction, characterization of Astragalus polysaccharides and its immune modulating activities in rats with gastric cancer. Carbohyd Polym. 2009:78(4):738-42.

26. Jin M, Huang Q, Zhao K, Shang P. Biological activities and potential health benefit effects of polysaccharides isolated from Lycium barbarum L. Int J Biol Macromol. 2013;54:16-23.

27. Schepetkin IA, Quinn MT. Botanical polysaccharides: macrophage immunomodulation and therapeutic potential. Int Immunopharmacol. 2006;6(3):317-33.

28. Sun Y. Structure and biological activities of the polysaccharides from the leaves, roots and fruits of Panax ginseng CA Meyer: An overview. Carbohyd Polym. 2011;85(3):490-9.

29. Hong-quan LI. Analysis on chemical components and structure of Astraglus polysaccharides [J]. J Tradit Chinese Vet Med. 2008:5:2.

30. Zhang N, Li J, Hu Y, Cheng G, Zhu X, Liu F, et al. Effects of astragalus polysaccharide on the immune response to foot-and-mouth disease vaccine in mice. Carbohyd Polym. 2010;82(3):680-6.

31. Schalm OW, Carroll EJ, Jain NC. Bovine mastitis. In: Bovine mastitis. a symposium. Philadelphia, USA: Lea \& Febiger; 1971.

32. Sun $H$, Xue F, Qian $K$, Fang $H$, Qiu $H$, Zhang $X$, et al. Intramammary expression and therapeutic effect of a human lysozyme-expressing vector for treating bovine mastitis. J Zhejiang Univ Sci B. 2006;7(4):324-30.

33. Rainard P, Riollet $C$. Innate immunity of the bovine mammary gland. Vet Res. 2006;37(3):369-400.

34. Moroni P, Sgoifo Rossi C, Pisoni G, Bronzo V, Castiglioni B, Boettcher PJ, Relationships between somatic cell count and intramammary infection in buffaloes. J Dairy Sci. 2006;89(3):998-1003.

35. Kitchen BJ, Kwee WS, Middleton G, Andrews RJ. Relationship between the level of $\mathrm{N}$-acetyl- $\beta$-D-glucosaminidase (NAGase) in bovine milk and the presence of mastitis pathogens. J Dairy Res. 1984:51(01):11-6.

36. Pyörälä S. Indicators of inflammation in the diagnosis of mastitis. Vet Res. 2003:34(5):565-78.

37. Pyörälä S, Pyörälä E. Accuracy of Methods Using Somatic Cell Count and $\mathrm{N}$-Acetyl- $\beta$-D-Glucosaminidase Activity in Milk to Assess the Bacteriological Cure of Bovine Clinical Mastitis. J Dairy Sci. 1997;80(11):2820-5. 
38. Bitter T, Muir HM. A modified uronic acid carbazole reaction. Anal Biochem. 1962:4(4):330-4

39. Barnes-Pallesen FD, Blackmer P, Britten A, Bushnell RB, Van Damme DM, Welcome F. Laboratory and field handbook on bovine mastitis. Arlington, VA: Natl. Mastitis Counc; 1987.

40. Brown RW, Barnum DA, Jasper DE, McDonald JS, Schultze WD. Microbiological procedures for use in the diagnosis of bovine mastitis Natl. Arlington, VA: Mastitis Counc. Inc; 1981. p. 16

Submit your next manuscript to BioMed Central and take full advantage of:

- Convenient online submission

- Thorough peer review

- No space constraints or color figure charges

- Immediate publication on acceptance

- Inclusion in PubMed, CAS, Scopus and Google Scholar

- Research which is freely available for redistribution 